\title{
Characterization of mutations in 22 females with X-linked dominant chondrodysplasia punctata (Happle syndrome)
}

Gail E. Herman, $M D, P h D^{1}$, Richard I. Kelley, MD, $P h D^{2}$, V. Pureza ${ }^{3,4}$, D. Smith ${ }^{3,5}$, Kevin Kopacz, MS ${ }^{1}$, James Pitt, BSc (Hons) ${ }^{6}$, Rebecca Sutphen, $M^{8}$, Leslie J. Sheffield, FRACP ${ }^{6,7}$, and Aida B. Metzenberg, MA, PhD ${ }^{3}$

\begin{abstract}
Purpose: Human X-linked dominant chondrodysplasia punctata (CDPX2) or Happle syndrome is associated with mutations in the human emopamil binding protein (EBP), a $\Delta^{8}$ - $\Delta^{7}$-sterol isomerase involved in cholesterol biosynthesis. The purpose of the current study was to determine the spectrum of EBP mutations in females with CDPX2 and the utility of biochemical screening for the disorder by analysis of plasma sterols. Methods: Genomic sequencing of the coding exons of the human $\Delta^{8}-\Delta^{7}$-sterol isomerase gene was performed on DNA from 26 females with suspected X-linked dominant chondrodysplasia punctata. Clinical data and sterol analyses were obtained for 24 and 23 of the patients, respectively. Results: Mutations in the human EBP $\Delta^{8}-\Delta^{7}$-sterol isomerase gene were found in 22 (85\%) of 26 females studied, including 20 (91\%) of 22 patients who demonstrated an abnormal sterol profile. Thirteen of the mutations have not been reported previously. All of the females in whom mutations were found demonstrated typical skin manifestations of CDPX2, and all but one had a skeletal dysplasia. Conclusions: Plasma sterol analysis was a highly specific and sensitive indicator of the presence of an EBP mutation in females with suspected CDPX2, including a clinically unaffected mother of a sporadic case. No clear genotype/phenotype correlations were ascertained, probably because phenotypic expression is influenced substantially by the pattern of X-inactivation in an affected female. Genet Med 2002:4(6):434-438.
\end{abstract}

Key Words: X-linked dominant chondrodysplasia punctata, Happle syndrome, emopamil binding protein, $\Delta^{8}-\Delta^{7}$. sterol isomerase

Chondrodysplasia punctata is a term used to describe several genetic and acquired disorders in which there is abnormal punctate calcification of the epiphyses of the long bones during infancy. ${ }^{1}$ The X-linked dominant form of chondrodysplasia punctata (CDPX2; OMIM 302960, also known as ConradiHunermann or Happle syndrome) is a rare human developmental disorder. It is characterized by a skeletal dysplasia that may include asymmetric, often rhizomelic, shortening of the limbs and scoliosis. The diagnostic radiographic finding of epiphyseal stippling is usually more widespread in this form of chondrodysplasia punctata than in others, and it may include stippling of the vertebral column and tracheal cartilage. ${ }^{1}$ Skin

From the ${ }^{1}$ Children's Research Institute and Department of Pediatrics, The Ohio State University, Columbus, Ohio, ${ }^{2}$ Kennedy Krieger Institute, Baltimore, Maryland; ${ }^{3}$ Department of Biology, California State University, Northridge, California; ${ }^{4}$ Hahnemann School of Medicine, Philadelphia, Pennsylvania; ${ }^{5}$ College of Medicine, University of California, Davis, California; ${ }^{6}$ Genetic Health Services Victoria; ${ }^{7}$ The Murdoch Children's Research Institute, University of Melbourne, Parkville, Melbourne, Victoria, Australia; and ${ }^{8}$ All Children's Hospital, St. Petersburg, Florida.

Gail E. Herman, MD, PhD, Children's Research Institute, 700 Children's Drive, Room W403, Columbus, $\mathrm{OH} 43205$.

Received: May 7, 2002.

Accepted: August 6, 2002.

DOI: 10.1097/01.GIM.0000035618.70404.F9 abnormalities include a patterned, hyperkeratotic, erythematous eruption that is typically present at birth but partially or completely resolves in the first few weeks of life. Cicatricial alopecia, variable ichthyosis, follicular atrophoderma, and residual pigmentary abnormalities are common. Congenital cataracts and occasional microophthalmia, as well as renal, cardiac, and central nervous system malformations have also been described in these patients (reviewed by Herman ${ }^{2}$ ). The asymmetry or patterned distribution of the skin findings reflects the process of random $\mathrm{X}$-inactivation in affected, heterozygous females.

In 1999 the gene that is altered in CDPX2 was identified based on the finding of abnormally elevated levels of the cholesterol precursors cholest-8(9)-en-3 $\beta$-ol and 8-dehydrocholesterol (8-DHC) in affected human patients, ${ }^{3,4}$ as well as by homology to the defective gene in the tattered mouse. ${ }^{5}$ The enzyme defect occurs in a $\Delta^{8}-\Delta^{7}$-sterol isomerase involved in postsqualene cholesterol biosynthesis. The gene encoding this enzyme, called EBP (OMIM 300205), was originally identified as a receptor for the calcium antagonist emopamil and is known to bind a diverse group of compounds, including tamoxifen. ${ }^{6}$ It has been localized to chromosome band Xp11.22p11.23. ${ }^{7}$ Mutations in the EBP gene were initially identified in 13 unrelated CDPX2 females (Refs. 4 and 5; patients 2 and 6 in 
Refs. 4 and 5 being identical). Subsequently, 13 additional females with $E B P$ mutations have been reported. ${ }^{8-10}$

To understand the range of mutations in the $E B P$ gene associated with CDPX2 and to correlate the sterol abnormalities and clinical findings with the molecular data, we have analyzed an additional 26 females with suspected CDPX2. Mutations were identified in 22 females, and 13 of these mutations are novel. Elevated 8-DHC and cholest-8(9)-en-3 $\beta$-ol levels in plasma or in cultured lymphoblastoid cells were strongly associated with the finding of a mutation in the EBP gene.

\section{MATERIALS AND METHODS}

Twenty-six females with a clinical diagnosis of CDPX2 were referred for study. Fourteen of the patients were ascertained on the basis of a clinical diagnosis or the presence of radiologic evidence of stippling of one or more epiphyses. Twelve were enrolled after an abnormal sterol profile analysis performed in the Clinical Mass Spectrometry Laboratory, Kennedy Krieger Institute (Baltimore, MD), and clinical information was subsequently obtained where possible. Blood or skin samples were obtained for molecular studies after informed consent and protocols approved by the appropriate institutional human subjects review boards. Clinical descriptions of Patients 2 and 10 have been reported by DiPreta et al. ${ }^{11}$ and Sutphen et al., ${ }^{12}$ respectively. For two of the patients, no clinical information was available. Sterol analyses of plasma or cultured lymphoblasts were performed in 23 of the cases as previously described. ${ }^{3,4}$ Genomic DNA was extracted from fresh blood samples or from cultured cell lines using standard protocols. Direct cycle sequencing of PCR-amplified DNA representing the coding exons (2-5) of the human EBP gene was performed for each patient sample as described ${ }^{4,5}$ on an ABI 377 automated sequencer. The heterozygous mutations were identified on both DNA strands and/or confirmed by sequencing of several cloned PCR products. Exon 1, a 5'-noncoding exon, was scanned for mutations only if a mutation was not detected in exons $2-5$.

\section{RESULTS}

Mutations in the EBP gene were found in 22 (85\%) of the 26 patients studied (Table 1). In 1999, Kelley et al. ${ }^{3}$ reported abnormal elevated levels of 8 -DHC and cholest-8(9)-en-3 $\beta$-ol in five females with CDPX2 or sporadic lethal CDP, consistent with an enzymatic deficiency of $\Delta^{8}-\Delta^{7}$-sterol isomerase. Subsequently, similar abnormalities of sterol metabolism were reported in four additional females with CDPX2 and EBP mutations. ${ }^{4,9}$ Twenty of our patients in which a mutation in the $E B P$ gene was detected had a sterol analysis performed. In all, the typical elevations in 8-DHC and cholest-8(9)-en-3 $\beta$-ol were identified (Table 1).

In four females, no mutation in the $E B P$ gene was detected: Patients 23-25 were reported to have skin and skeletal features consistent with a diagnosis of CDPX2, and typical, abnormal sterol profiles were found in the two girls in whom the test was performed. The only clinical signs in the fourth female (Patient 26) were epiphyseal stippling and asymmetric shortening of one limb, and she was subsequently found to exhibit a normal sterol profile. $\mathrm{We}^{5}$ and others ${ }^{9}$ have previously reported an absence of $E B P$ mutations in four unrelated females with puncta and skeletal findings only. Possible explanations for our inability to detect a mutation in the three females with "classic CDPX2" would include the presence of a heterozygous deletion undetectable by our current methods of analysis, a mutation in a regulatory region of the $E B P$ gene, or, perhaps, a phenocopy with a mutation in another related gene.

As shown in Table 1, mutations were encountered in all of the coding exons of the gene, with the majority of mutations, $18(82 \%)$ of 22 , in exons 2 and 4 . Thirteen of the mutations have not been previously reported, including three associated with small genomic rearrangements (deletions and insertions) and the single mutation involving the donor splice site in intron 4 (Patient 20). We identified nonsense mutations in six patients, three of which were novel (W61X, R110X, and W135X). These mutations, as well as those in the three patients with frameshifts and truncated proteins, would be expected to produce functional null alleles.

There were 12 missense mutations, 6 of which were novel (R62W, C72Y, G130 V, G157S, G173R, and W196S). Analysis of the amino acid sequence of the EBP protein predicts that it is a Type I integral membrane protein with four potential transmembrane domains and a potential site for cAMP-dependent protein kinase phosphorylation (Ref. 6 and see Fig. 1). Sequence data for the human, guinea pig, rat, and mouse EBP genes are available. Significantly, all of the missense mutations identified in this study alter amino acids that are conserved across these four species, suggesting that these residues are critical to the function of the protein. The $\mathrm{C} 72 \mathrm{Y}$ residue in membrane-spanning domain 1 is predicted to be in close juxtaposition to either $\mathrm{C} 120$ or $\mathrm{C} 127$ in membrane-spanning domain 2 such that the mutation $\mathrm{C} 72 \mathrm{Y}$ could affect disulfide bridging and, hence, the three dimensional conformation of the protein. Finally, Braverman et al. ${ }^{4}$ have previously demonstrated the functional significance of the recurrent missense mutation E80K by its inability to correct abnormal sterol profiles in a yeast complementation assay.

Five of the mutations were recurrent, including three previously reported (R63X, E80K, and R147H) and two reported here for the first time (R62W and W135X). Six of the single base alterations (R62W, R63X, E80K, R110X, R147H, and G173R) found in 11 of the patients occurred at CpG dinucleotides and represent alterations that could be associated with the deamination of a methylated cytosine residue. These sites include all of the recurrent mutations except for W135X and are likely "hotspots" for mutation.

\section{DISCUSSION}

There was no clear evidence of a genotype-phenotype correlation between mutations, levels of sterol intermediates, and the types of physical abnormalities found in affected females. Ikegawa et al. have suggested that females with nonsense or frameshift mutations producing a nonfunctional protein are 
Table 1

Summary of patients and mutations identified

\begin{tabular}{|c|c|c|c|c|c|c|c|c|c|}
\hline \multirow[b]{2}{*}{ Patient } & \multirow{2}{*}{$\begin{array}{l}\text { Family } \\
\text { history }\end{array}$} & \multirow{2}{*}{$\begin{array}{c}\text { Abnormal } \\
\text { sterol } \\
\text { profile }^{a}\end{array}$} & \multirow[b]{2}{*}{ Exon } & \multirow[b]{2}{*}{ Mutation $^{b}$} & \multirow[b]{2}{*}{ Amino acid } & \multicolumn{3}{|c|}{ Clinical findings ${ }^{c}$} & \multirow[b]{2}{*}{ Other } \\
\hline & & & & & & Skin & Skeletal & Cataracts & \\
\hline 1 & - & + & 2 & $\begin{array}{l}\text { c.122delTCTTAG } \\
\text { and c.134insC }\end{array}$ & Frameshift/truncation & + & + & Bilateral & $\begin{array}{l}\text { Normal IQ; bilateral sensorineural deafness; } \\
\text { hip and knee contractures }\end{array}$ \\
\hline 2 & - & + & 2 & c.166-167ins T & Frameshift/truncation & + & + & Right & Bilateral clubfeet; right postaxial polydactyly \\
\hline 3 & - & + & 2 & c. $183 \mathrm{G}>\mathrm{A}$ & W61X & + & $+^{d}$ & Left & Mild sensorineural deafness; normal IQ \\
\hline 4 & - & + & 2 & c. $184 \mathrm{C}>\mathrm{T}$ & R62W & + & + & $?$ & Normal IQ \\
\hline 5 & - & + & 2 & c. $184 \mathrm{C}>\mathrm{T}$ & $\mathrm{R} 62 \mathrm{~W}$ & + & $\stackrel{+}{+}$ & - & Normal IQ \\
\hline 6 & - & + & 2 & c. $187 \mathrm{C}>\mathrm{T}$ & R63X & + & + & Bilateral & Hydronephrosis; normal IQ \\
\hline 7 & - & + & 2 & c. $187 \mathrm{C}>\mathrm{T}$ & R63X & + & + & + & $\begin{array}{l}\text { Normal IQ; mildly Smith-Lemli-Opitz-like } \\
\text { facies }\end{array}$ \\
\hline 8 & $?$ & + & 2 & c. $215 \mathrm{G}>\mathrm{A}$ & $\mathrm{C} 72 \mathrm{Y}$ & + & - & $?$ & \\
\hline 9 & - & + & 2 & c. $238 \mathrm{G}>\mathrm{A}$ & $\mathrm{E} 80 \mathrm{~K}$ & $?$ & + & $?$ & \\
\hline 10 & + & ND & 2 & c. $238 \mathrm{G}>\mathrm{A}$ & $\mathrm{E} 80 \mathrm{~K}$ & + & + & + & \\
\hline 11 & - & ND & 2 & c.268-269insCT & Frameshift/truncation & + & + & - & Postaxial polydactyly; deceased \\
\hline 12 & - & + & 3 & c. $328 \mathrm{C}>\mathrm{T}$ & R110X & + & + & Bilateral & Normal IQ \\
\hline 13 & $?$ & + & 4 & c. $389 \mathrm{G}>\mathrm{T}$ & G130V & + & + & $?$ & Fetus terminated at 28 weeks \\
\hline 14 & $?$ & + & 4 & c. $404 \mathrm{G}>\mathrm{A}$ & W135X & + & $\begin{array}{c}+ \\
\text { (no stippling) }\end{array}$ & $?$ & \\
\hline 15 & - & + & 4 & c. $405 \mathrm{G}>\mathrm{A}$ & W135X & + & + & $?$ & Normal IQ \\
\hline 16 & - & + & 4 & c. $440 \mathrm{G}>\mathrm{A}$ & $\mathrm{R} 147 \mathrm{H}$ & $?$ & + & $?$ & \\
\hline 17 & - & + & 4 & c. $440 \mathrm{G}>\mathrm{A}$ & $\mathrm{R} 147 \mathrm{H}$ & + & + & Left & Microcephaly; developmental delay; seizures \\
\hline 18 & - & + & 4 & c. $440 \mathrm{G}>\mathrm{A}$ & $\mathrm{R} 147 \mathrm{H}$ & + & + & + & \\
\hline 19 & - & + & 4 & c. $469 \mathrm{G}>\mathrm{A}$ & G157S & + & + & Bilateral & Tethered cord \\
\hline 20 & $?$ & + & $\begin{array}{c}\text { Intron } \\
\quad 4\end{array}$ & c. $469+1 \mathrm{G}>\mathrm{A}$ & Donor splice site & ? & $?$ & $?$ & \\
\hline 21 & $?$ & + & 5 & c. $517 \mathrm{G}>\mathrm{A}$ & G173R & $?$ & $?$ & $?$ & \\
\hline 22 & - & + & 5 & c. $587 \mathrm{G}>\mathrm{C}$ & W196S & + & + & $?$ & Cervical myelopathy; deceased \\
\hline 23 & - & ND & & & & + & + & $?$ & \\
\hline 24 & - & + & & & & + & + & $?$ & \\
\hline 25 & - & + & & & & + & + & $?$ & \\
\hline 26 & - & - & & & & - & + & - & \\
\hline
\end{tabular}

Abbreviations and symbols used are as follows: + indicates the feature was present; - indicates that it was absent; ? indicates that no information was available. ND, not determined.

${ }^{a}$ Patients with an abnormal sterol profile had significant elevations in 8-dehydrocholesterol (8-DHC) and cholest-8(9)-en-3 $\beta$-ol [8(9) chl]. The mean cholesterol level in a total of 53 samples analyzed was $150 \mathrm{mg} / \mathrm{dL}$ with a standard deviation of 46.2 and a range of $35.6-244$. The mean 8 -DHC was $3.8 \mu \mathrm{g} / \mathrm{mL}$ with a standard deviation of 3.5 and a range of $0-14.9$ (normal $<0.1$ ), and the mean $8(9)$ chl was $9.8 \mu \mathrm{g} / \mathrm{mL}$ with a standard deviation of 10.3 and a range of $0.14-41.3$ (normal $<$ 0.1 .

${ }^{b}$ Mutations are designated as recommended, ${ }^{18}$ with the first nucleotide of the initiator methionine numbered as 1.

'The presence of skin findings included all or most of the following: patterning ichthyosis and/or erythroderma at birth, patchy alopecia, follicular atrophoderma, and residual pigmentary abnormalities or ichthyosis. Skeletal findings included shortening of the limbs, usually asymmetric, and infantile epiphyseal stippling, unless otherwise noted.

${ }^{d}$ The patient was born in Mexico, where scoliosis, a left cataract, and "scaly skin" were noted. No stippling of the epiphyses was detected when the first x-rays were obtained in this country at 6 years of age.

likely to demonstrate the complete phenotype including skin, skeletal, and ocular manifestations of their disease. They found that patients with missense mutations did not consistently demonstrate all clinical features, particularly ocular abnormal- ities. ${ }^{9}$ All of the females with $E B P$ mutations listed in Table 1 for whom clinical information was available demonstrated typical skin abnormalities of CDPX2, and all but one (Patient 8) had skeletal findings. A lack of stippling on $x$-rays in infancy 


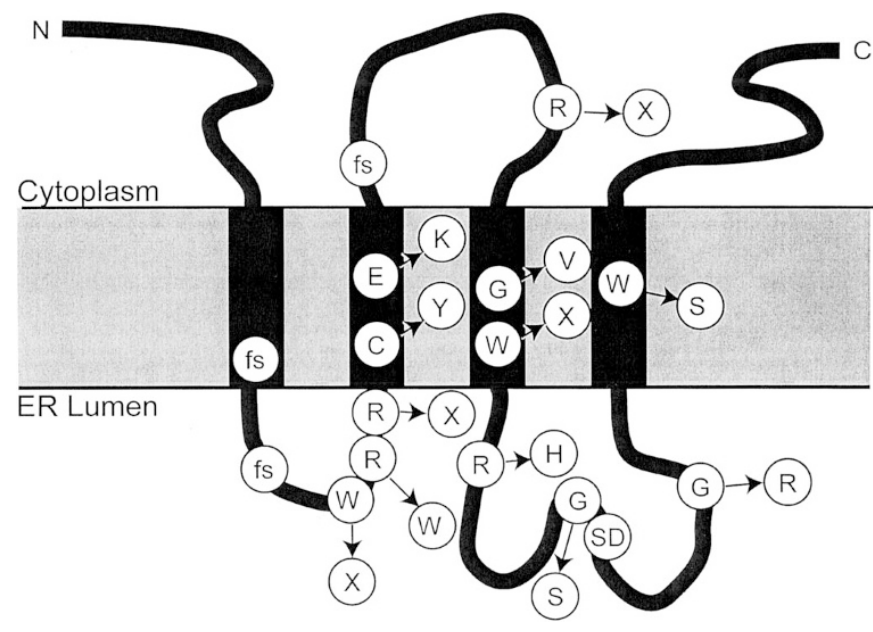

Fig. 1 EBP mutations identified in this study. Predicted topology of the EBP protein with four membrane spanning domains is shown as described. ${ }^{6}$ Mutations are designated using the single-letter amino acid code. Recurrent mutations are shown only once. Fs, frameshift mutation; SD, splice donor mutation; X, nonsense mutation.

was documented in two cases (Patients 5 and 14), although this finding is considered a hallmark of the disorder. Unfortunately, complete clinical information, particularly with respect to ocular findings, was difficult to obtain for many of our current cases. However, at least one of our patients with a frameshift mutation and truncated protein (Patient 11) lacked cataracts. Ikegawa et al. ${ }^{9}$ demonstrated random $\mathrm{X}$-inactivation in peripheral blood leukocytes from three CDPX2 patients as well as from their unaffected mothers. Major effects on the severity of the clinical phenotype and the expressivity of a particular mutation are likely to reflect the pattern and timing of X-inactivation as much as or more than the exact mutation itself.

There was a high correlation between detection of the characteristic abnormal sterol metabolites 8-DHC and cholest$8(9)$-en- $3 \beta$-ol and identification of a mutation in the EBP gene (20 mutations identified in 22 females with abnormal sterol profiles or $91 \%$ ). Thus sterol analysis of females with suspected CDPX2 is a useful screening tool with a relatively high specificity and sensitivity. It may be particularly helpful in differentiating the rhizomelic form of chondrodysplasia punctata (RCDP; OMIM 215100), which is associated with peroxisomal abnormalities, elevated plasmalogen levels, and a much poorer prognosis, ${ }^{13}$ from CDPX2. In fact, one of the patients studied here (Patient 6) was originally suspected to have RCDP based on the presence of severe, symmetric rhizomelia at birth. However, plasmalogen studies were normal and subsequent plasma sterol levels were compatible with CDPX2 as was her clinical course (G. Herman, unpublished, 2000).

In the majority of familial cases of CDPX2, the severity of the physical manifestations increases in succeeding generations (anticipation). ${ }^{2,12,14}$ This phenomenon appears to be explained, at least in part, by the finding of gonadal and/or somatic mosaicism in at least two families. ${ }^{8}$ In addition, somatic mosaicism has been reported in two males with features of CDPX2, normal karyotypes, and heterozygous mutations in the EBP gene. ${ }^{15,16}$ Finally, a single male with microcephaly and significant neurologic impairment, a unilateral cataract, patchy hypopigmentation, renal anomalies, but no epiphyseal stippling or skeletal dysplasia was found to have a novel hemizygous EBP missense mutation, L18P. ${ }^{17}$ Only one of our cases was known to be familial (Patient 10). Clinical features in three generations of affected individuals in this family, including an affected male with a 47,XXY karyotype, have been reported. ${ }^{12}$

A plasma sterol analysis was performed on the mothers of seven of the females with sporadic CDPX2 listed in Table 1. For four of the cases (Patients 2, 7, 16, and 22), a normal plasma sterol profile was obtained, and no mutation was detected in DNA prepared from the mother's peripheral blood leukocytes (data not shown). The mother of Patient 3 had an abnormal sterol profile, and the heterozygous G183A mutation was detected in her peripheral blood DNA. She was clinically unaffected. In addition to her affected daughter, she had delivered a healthy boy and girl and had a history of one miscarriage.

There were no inconsistencies between the ability to detect an abnormal sterol profile in an apparently unaffected mother and the detection of a mutation in the same individual. However, the number of samples studied is small. The mothers of Patients 9 and 15 had normal and abnormal sterol profiles, respectively, but no DNA was available for confirmation of the presence of a mutation. Finally, no mutation was detected in DNA from peripheral blood of the mothers of Patients 4, 6, and 17 , and sterol analyses were not performed. Since germline mosaicism has been reported in this disorder, ${ }^{8}$ the inability to detect a mutation in the mother of a sporadic case does not completely eliminate the risk of recurrence for a woman who has an affected daughter.

In summary, we have detected mutations in the human $\Delta^{8}$ $\Delta^{7}$-sterol isomerase gene in 22 females with CDPX2, extending the total number of confirmed mutations in unrelated females to $48.4,5,8-10$ This study represents the first in which extensive analysis of plasma sterols was used and demonstrates its utility as a screening method, including the detection of an asymptomatic carrier female (mother of Patient 3). More detailed clinical studies and long-term follow-up will be necessary to ascertain whether any genotype-phenotype correlations exist in this disorder and to examine further the utility of biochemical screening in asymptomatic mothers of sporadic cases.

\section{Acknowledgments}

This work was supported in part by NIH R01 HD38572 (G.E.H.). The authors thank referring clinicians for providing patient samples and clinical information.

\section{References}

1. Taybi H, Lachman RS, editors. Radiology of syndromes, metabolic disorders, and skeletal dysplasias, 4th ed. St Louis: Mosby, 1996:777-786.

2. Herman GE. X-linked dominant disorders of cholesterol biosynthesis in man and mouse. Biochim Biophys Acta 2000;1529:357-373.

3. Kelley RI, Wilcox WG, Smith M, Kratz LE, Moser AB, Rimoin DS. Abnormal sterol metabolism in patients with Conradi-Hunermann-Happle syndrome and sporadic lethal chondrodysplasia punctata. Am J Med Genet 1999;83:213-219.

4. Braverman N, Lin P, Moebius FF, Obie C, Moser A, Glossmann H, Wilcox WR, Rimoin DL, Smith M, Kratz LE, Kelley RI, Valle D. Mutations in the gene encoding 


\section{Herman et al.}

$3 \beta$-hydroxysteroid- $\Delta 8, \Delta 7$-isomerase cause X-linked dominant Conradi-Hunermann syndrome. Nat Genet 1999;22:291-294.

5. Derry JM, Gormally JE, Means GD, Zhao W, Meindl A, Kelley RI, Boyd Y, Herman GE. Mutations in a $\Delta 8-\Delta 7$ sterol isomerase in the tattered mouse and X-linked dominant chondrodysplasia punctata. Nat Genet 1999;22:286-290.

6. Hanner M, Moebius FF, Weber F, Grabner M, Striessnig J, Glossmann H. Phenylalkylamine $\mathrm{Ca} 2+$ antagonist binding protein: molecular cloning, tissue distribution, and heterologous expression. J Biol Chem 1995;270:7551-7557.

7. Schindelhauer D, Hellebrand H, Grimm L, Bader I, Meitinger T, Wehnert M, Ross $\mathrm{M}$, Meindl A. Long-range map of a 3.5-Mb region in Xp11.23-22 with a sequenceready map from a 1.1-Mb gene-rich interval. Genome Res 1996;6:1056-1069.

8. Has C, Bruckner-Tuderman L, Muller D, Floeth M, Folkers E, Donnai D, Traupe, H. The Conradi-Hunermann-Happle syndrome (CDPX2), and emopamil binding protein: novel mutations, and somatic and gonadal mosaicism. Hum Mol Genet 2000;9:1951-1955.

9. Ikegawa S, Ohashi H, Ogata T, Honda A, Tsukahara M, Kubo T, Kimizuka M, Shimode M, Hasegawa T, Nishimura G, Nakamura Y. Novel and recurrent EBP mutations in X-linked dominant chondrodysplasia punctata. Am J Med Genet 2000;4:300-305

10. Becker K, Csikós M, Horváth A, Kárpáti S. Identification of a novel mutation in $3 \beta$-hydroxysteroid- $\Delta 8-\Delta 7$-isomerase in a case of Conradi-Hünermann-Happle syndrome. Exp Dermatol 2001;10:286-289.

11. DiPreta EA, Smith KJ, Skelton H. Cholesterol metabolism defect associated with Conradi-Hunerman-Happle syndrome. Int J Dermatol 2000;39:846-858.
12. Sutphen R, Amar MJ, Kousseff BG, Toomey KE. XXY male with X-linked dominant chondrodysplasia punctata (Happle syndrome). Am J Med Genet 1995;57: $489-492$.

13. Gould SJ, Raymond GV, Valle D. The peroxisome biogenesis disorders. In: Scriver CR, Beaudet AL, Sly WS, Valle D, editors. The metabolic and molecular bases of inherited disease. New York: McGraw-Hill, 2001:3181-3217.

14. Traupe H, Muller D, Atherton DJ, Kalter DC, Cremers FPM, van Oost BA, Ropers HH. Exclusion mapping of the X-linked dominant chondrodysplasia punctata/ichthyosis/cataract/short stature (Happle) syndrome: possible involvement of an unstable pre-mutation. Hum Genet 1992;89:659-665.

15. Metzenberg AB, Kelley R, Smith D, Kopacz K, Sutphen R, Sheffield L, Herman G. Mutations in chondrodysplasia punctata, X-linked dominant type (CDPX2). Am J Hum Genet 1999;65:A480.

16. Aughton DJ, Kelley RI, Metzenberg A, Pauli RM. Molecular confirmation of somatic mosaicism in a karyotypically normal male with X-linked dominant chondrodysplasia punctata 2 (CDPX2). Am J Hum Genet 2001;69:A299.

17. Milunsky JM, Maher TA, Metzenberg AB, Kelley RI. Molecular, biochemical, and phenotypic analysis of a male with X-linked dominant Conradi-HunermannHapple syndrome (CDPX2). Am J Hum Genet 2001;69:A494.

18. Antonarakis SE, and the Nomenclature Working Group. Recommendations for a nomenclature system for human gene mutations. Hum Mutat 1998;11:1-3. 